\title{
LA IMAGEN DEL AVE FÉNIX EN LA POESIA DE CANCIONERO. NOTAS PARA UN ESTUDIO
}

El presente estudio se desgaja, inicialmente, de un complejo mayor sobre las imágenes del reino animal en la poesía cancioneril en relación al petrarquismo y, sobre todo, con miras puestas en la fundamentación imaginística de la poesía del siglo XVI ', dentro del marco filológico de la intertextualidad. Pero son precisamente estos intereses, en un principio primordiales, los que me obligan y me llevan a la revisión de la poesía cortesana del siglo XV, la poesía cancioneril o de cancionero. Y por ésta entiendo la que se produce en las cortes españolas desde el último tercio del siglo XIV hasta el fin del reinado de los $\mathrm{RRCC}^{2}$, recogida y transmitida por lo común en cuerpos colectivos y fuertemente vinculada, en sus orígenes, a la antigua poesía provenzal y galaicoportuguesa, evolucionando, naturalmente, hacia influjos clásicos e italianos.

Mis pesquisas, dentro de estos límites cronológicos y de las posibilidades que ofrecen los numerosos cancioneros colectivos, felizmente ya inventariados en su casi totalidad ', se han circunscrito exclusivamente a los cancioneros impresos, con dos límites precisos e ineludibles: el Cancionero de Baena, por una parte, y el Cancionero General de Hernando del Castillo, por otra, con alguna incursión esporádica a otros cancioneros más tardíos, teniendo siempre a la vista el Cancionero Castellano del Siglo XV de Foulché Delbosc, pero sin pretensión, claro está, de agotar en la citas, forzosamente limitadas, el material existente.

Por imagen entiendo no sólo la representación de algo que existe realmente como ser material o como fruto de la imaginación, sino también, y dentro ya de

1 Imágenes petrarquistas en la lírica española del Renacimiento. Repertorio, Barcelona, PPU, «Estudios de Literatura Española y Comparada», 1990.

2 Vid., al respecto, las apreciaciones de Nicasio SALVADOR, La poesía cancioneril. El cancionero de Estúnigiga, Madrid, Alhambra, 1977, pp. 10 y ss.

' Naturalmente estoy pensando en las magnas obras de catalogación iniciadas por Jacqueline STEUNOU y Lothar KNAPP, Bibliografía de los Cancioneros Castellanos del Siglo XV y Repertorio de sus Géneros Poéticos, París, CNRS, 1975, 2 vols., y culminadas con esmero por Brian Dutron, Catálogo-Indice de la Poesia Cancioneril del Siglo XV. Madison, The Hispanic Seminary of Medieval Studies, 1982, 2 vols. y ahora en 6 vols., Salamanca, Biblioteca del S. XV, 1991-92, la edición. 
una concepción literario-retórico-lingüística, como la expresión de una analogía ${ }^{4}$, de una comparación o metáfora; como eslabón de un entramado alegórico o también como microtema 'o núcleo de un motivo: motivo eminentemente mítico en este caso: imagen mítica la nuestra, por lo tanto.

$\mathrm{Y}$, en efecto, desde muy antiguo, detectamos en textos de poetas e historiadores clásicos y en las páginas de los más prestigiosos bestiarios medievales (prolegómenos, en parte y en este sentido, de los libros de emblemas renacentistas y barrocos, que continuarán en pareja línea) ${ }^{6}$, la presencia de un ave fantástica y única de nombre fénix, procedente del fabuloso Oriente ', cuyo plumaje reflejaba los colores del sol y de la púrpura y que después de una larguísima existencia moría en medio de plantas aromáticas, renaciendo rejuvenecida de sus propias cenizas, para empezar otra vez una vida nueva, sin dejar de ser ella misma. Avis rara, bella entre las bellas, altera e sola, en relación al aire, símbolo solar, como el águila con la que a veces se identifica y en la que también en determinados casos se transforma. En fin, imagen ígnea, dominada por la muerte y la resurrección en la vida y en el amor.

Por fortuna, de estos poetas e historiadores antiguos y de otros muchos más, e incluso, de la paulatina cristianización del mito desde Lactancio, poseemos ya estudios realizados y solventes, lo que facilita grandemente nuestra tarea. El clásico libro de Jean Hubaux y Maxime Leroy, Le mithe du phénix dans les littératures grecque et latine ${ }^{8}$, por ejemplo, nos ofrece buen

${ }^{4}$ Michel LE GUERN, Sémantique de la métaphore et de la méthonymie, Paris, Larousse Université, 1973.

' Vid., en este sentido, el op. de Ulrich WeISSTEIN, Introducción a la literatura comparada, Barcelona, Ensayos Planeta, 1975, pp. 265 y ss., Asimismo la obra de Kenneth BURKE, «Imagery at Face Value» en $A$ Rhetoric of Motives, New York-Prentice Hall, INC., 1950, pp. 17-19, en donde aparece la imagen poética como núcleo del motivo.

- "Les Livres d'Emblèmes ont remplacé les Bestiaires au XVIe siècle»: Hélène NAYS, Les Animaux dans la poésie française de la Renaissance, Paris, Didier, 1961, pp. 322 y ss.

La leyenda del fénix parece auténticamente de origen egipcio, puesto que, en principio, la encontramos en el libro de Heródoto (Hist., II, 73) y porque, además, los escritores antiguos que asimismo relatan el mito, tal, por ejemplo, Ovidio (Met. XV, 392-407), Plinio ( $H N$., X, 4 y 7) o Tácito (Anales, VI, 28), insisten en esta procedencia. Vid., a este propósito, el mencionado estudio de Hélène NAYs, p. 336 y ss. Por lo que se refiere a la interpretación del mito en relación a la tradición mística alejandrina de Hermes Trimegisto, tan de moda entre los humanistas florentinos (Ficino, Pico), puede consultarse la obra de A. J. FESTUGIÈRE, «Le symbole du phénix et le mysticisme hermétique», Hermétisme et mystique païenne, Paris, Aubier-Montaigne, 1973, pp. 256-260. Y en lo que concierne al tratamiento espiritualista del mito por Horapolo del Nilo (eroglificos I, 34) el estudio y textos de Ángel ANGLADA ANFruns, El mito del ave fénix, Barcelona, Bosch, 1983, especialmente p. 181.

${ }^{8}$ Paris, Droz, 1939. 
acopio de textos antiguos - Lactancio Claudiano, Pseudo Baruch, Phisiologos griego y de Viena- y de significaciones simbólicas del ave, presentándose como una interesante y bien fundamentada monografía del mito en la antigüedad. Más recientemente, Angel Anglada Anfruns nos proporciona en su obra, El mito del Ave Fénix', una buena selección de textos antiguos, medievales y renacentistas -Claudiano, Ovidio, Pomponio Mela, Plinio, Tácito, San Pablo, Eusebio de Cesárea, Epifanio, San Ambrosio, San Gregorio De Tours, Isidoro de Sevilla, Máximo Confesor, San Valerio Abad, Rábano Mauro, San Alberto Magno, Juan Pierio, Artemidoro Daldiano, Horapolo del Nilo- que completan los ofrecidos por Ignacio Malaxecheverría en su estudio, Bestiario medieval ${ }^{10}$, referidos a bestiarios y enciclopedias " y en donde se acopian textos del Physiologo griego, de Philippe de Thaün, Thibaut de Champagne, De bestiis et allis rebus, el Bestiario latino de Cambridge, el Tesoretto de Brunetto Latini, el Deleite de los corazones del persa Al-Qazwini, los relatos de los exóticos viajes de Mandeville o los Bestiaris catalanes, versiones del toscano y editados por Saverio Panuzio ${ }^{12}$. Del mismo modo, Jean Paul Clébert en su Bestiaire Fabuleux ${ }^{13}$ realiza una síntesis casi completa de las interpretaciones del ave fénix desde Solino, con referencias sensiblemente decantadas hacia los Padres de la Iglesia, línea que, asimismo, ilustra Eduard Urech en su estudio sobre los símbolos cristianos ${ }^{14}$. El ave fénix tiene detrás de sí, por lo tanto, un cúmulo de estudios considerable, de entre los que me he limitado a señalar los complexivos y principales. Es, por lo tanto, un mito bastante bien conocido en otras áreas y literaturas ${ }^{15}$, y es posible que resulte gratificante estudiarlo en la nuestra ${ }^{16}$.

9 Remitimos a esta obra cit. más arriba para una bibliografía selecta sobre el mito que nos excusamos copiar.

${ }^{10}$ Madrid, Siruela, 1986, pp. 120 y ss.

"Vid., a este propósito, las precisiones llevadas a cabo por Nicasio SALvadoR Miguel en la reseña de este libro, aparecida en «Insula», núm. 485-486, p. 9.

12 Barcelona, «Els Nostres Clàssics», núm. 91 y 92, 1963-64. En general puede consultarse, además, la obra de Florence Mc CULLOCH, Medieval latin and french bestiaries, Chapel Hill, The University of North Carolina Press, 1960.

${ }^{13}$ Paris, Albin Michel, 1971, pp. 298 y ss.

14 Dictionnaire des symboles cbrétiens, Neuchâtel, Delachaux et Niestle, 1972, pp. 147 y ss.

1s Vid., a parte del estudio de Jean Hubeaux y Maxime Leroy anteriormente citado, las obras de Flavio CATENAZZI, L'influsso dei provenzali sui temi e immagini della poesia siculo toscana, Brescia, Morcelliana, 1977, pp. 238 y ss., por lo que se refiere a la presencia de la imagen en el ámbito de la poesía de los trovadores provenzales y sicilianos. Asimismo el estudio de Walter PAGANI, Repertorio tematico della scuola poetica siciliana, Bari, Adriatica Editrice, 1968, pp. 447 y ss. Y, en relación al movimiento stilnovístico, la obra de Eugenio SAVONA, Repertorio temático del dolce stil nuovo, Bari, Adriatica Editrice, 1973, pp. 364 y ss.

${ }^{16}$ De ello me he ocupado ya, en relación a otros mitos e imágenes, dentro de unas 
La poesía de cancionero de la Edad Media, muy a la zaga en cantidad de las cotas que la imagen manifestará en nuestra poesía áurea, registra, sin embargo, marcas relevantes del mito y despliega un notable abanico de variantes significativas y posibilidades funcionales. La presencia de la imagen, con todo, es escasa, en especial, teniendo en cuenta la considerable cantidad de textos en los que, esporádicamente, se manifiesta. El fénix es, pues, avis rara en nuestros cancioneros; su presencia tardía, y su ausencia manifiesta en el más antiguo: el de Baena ", el más ligado a la poesía galaico portuguesa, en donde su vuelo tampoco se registra: ni en los cancioneros propiamente medievales ${ }^{18}$, ni en el castellanizante y con aires prerrenacentistas Cancioneiro Geral de García de Resende ${ }^{19}$; tal vez ello en relación con la escasa profusión de la impronta animalística en las cantigas galaico portuguesas; excepción hecha, naturalmente, de las de escarnio ${ }^{20}$.

Del mismo modo que su huella apenas se detecta en la antigua lírica popular hispánica, de la que, en el magno Corpus de Margit Frenk ${ }^{21}$, hallo un ejemplo anónimo, en la parte reservada a las Lamentaciones. Lamento de soledad, en este caso, que ilustra el fénix por su existencia única y sin par, con sus ventajas e invonvenientes:

coordenadas de intertextualidad petrarquista en la lírica del Renacimiento en mi estudio cit., Imágenes petrarquistas en la lírica española del Renacimiento, pp. 301-312.

1"Salvo error u omisión de mis pesquisas, realizadas en la edición crítica de José María AZÁCETA, Madrid, CSIC., 1966, 3 vols.

${ }_{18}$ Hemos revisado las ediciones siguientes: Cantigas d'amor dos trovadores galegoportugueses, ed. J.J. NUNES, Lisboa, Centro do Livro Brasileiro, 1972. Cantigas d'amigo dos trovadores galego-portugueses, ed. J.J. NUNES, Coimbra, Imprensa da Universidade, 1928 New York, Kraus Reprint Co., 1971, 3 vols. y Cantigas d'escarmbo e de mal dizer dos cancioneiros medievais galego-portugueses, ed. M. RODRIGUES-LAPA, Vigo, Galaxia, 1970.

19 He utilizado la edición de Andrée Crabbé Rocha, Lisboa, Centro do Livro Brasileiro, 1973, 5 vols.

${ }^{20}$ Donde, sin embargo, la presencia del fénix tampoco se registra. Vid., a este propósito, el estudio de Antoni ROSSELL, Las comparaciones animales en las cantigas de escarmio galaico protuguesas, "Actas del I Congreso de la Asociación Hispánica de Literatura Medievalw, Santiago de Compostela, Diciembre de 1985. Barcelona, PPU, 1988 pp. 552560. Vid., asimismo, y de manera general para los grandes géneros cancioneriles galaico portugueses, el muy cumplido estudio de M. BREA LÓPEZ, J.M. DíAZ DE BuSTAMANTE, I. GÓNZALEZ FÉRNANDEZ, Animales de referencia y animales de significación en la lírica gallego-portuguesa, «Boletín de Filología», XXIX (1984), pp. 75-100, donde, precisamente, en p. 86, subrayan los autores la ausencia de animales fantásticos, entre ellos el fénix, en el corpus de la lírica galaico-portuguesa.

21 Corpus de la Antigua Lírica Popular Hispánica, Madrid, Castalia, Nueva Biblioteca de Erudición Crítica, 1987, núm. 839, p. 380. 
Si el phénix es solo en el mundo también soy solo y sin segundo aunque llega mi pena al profundo ${ }^{22}$

De entre los ejemplos extraídos de la poesía propiamente cancioneril y elegidos para esta exposición, las manifestaciones que presenta la imagen abarcan varias posibilidades que pudiéramos dividir, por una parte, en la representación directa, por vía del relato, de uno o varios aspectos del mito presentado por los bestiarios con la correspondiente descripción ornamental de la imagen; por otra, la eleboración indirecta (como imago o exemplum), fruto ya de una comparación o translatio, con la confrontación de un referente que es, con mucho, la formulación que me parece más interesante.

El primero de los casos, podemos ejemplificarlo en textos de Pablo de Santa María, el obispo converso bisabuelo de Fray Íñigo de Mendoza, quien en Las Edades del Mundo, concretamente en la Séptima, nos proporciona la descripción del ave con casi todas las propiedades temporales, espaciales, suntuarias y transformacionales manifestadas en los bestiarios y comúnmente repetidas: el lugar de origen/visión del ave en Egipto o Arabia ${ }^{23}$, su belleza sin par, en suma su rareza; su semejanza con el águila ${ }^{24}$; la vistosidad de los colores de su plumaje en el que, desde Herodoto, no puede faltar el oro y el rojo, más el argentado que le asigna nuestro poeta ${ }^{25}$.

En tiempo de aqueste en Egipto se vio vna aue fermosa de colores mista,

la qual seiscientos años fue vista

22 Versos malos y endechas imperfectas, probablemente escritas por poetas que eran lectores de poesía culta sin llegar a ser doctos. Vid. sobre la estrofa cit., y la serie en la que se inserta, el artículo de Margit FrENK, Endechas anónimas del siglo XVI, "Studia Hispanica in Honorem R. Lapesa», Madrid, Gredos, 1974, II, pp. 245-268; pero, especialmente, pp. 247 y 256.

${ }^{23}$ La tierra del fénix suele ser variable según los autores antiguos: Arabia, India, Asiria, Egipto, Etiopía, pero, sin embargo, existe entre ellos (Heródoto, Tácito, Ovidio, Heliodoro, etc.) un denominador común: la ubicación de la morada en el general y legendario «lejano oriente». Vid. al respecto, "La morada del ave fénix» en el estudio cit. de Angel Anglada Anfruns, pp. 41 y ss.

${ }^{24}$ Característica ésta ya presente en Heródoto (Historia, II, 73); pero también en Plinio (Historia Natural, lib. X, 2, 3-5). Vid., al respecto, el cit. libro de Anglada Anfruns, p. 24, pero, especialmente, su «Selección de textos relativos al mito del ave fénix», en este caso, pp. 139 y ss.

25 Vemos que la "parte argentada» que asigna a la descripción del plumaje del fénix Pablo de Santa María, no tiene correspondiente directo con las descripciones más usuales del ave fabulosa, aunque Plinio (Historia Natural, X, 2, 3-5), asigna a la cola del fénix un color azul, nada lejano, por lo tanto, al argento. 
en tierra de Arabia, donde se mostro;
e nunca despues ni antes se fallo
que oviese entre todas otra ave ninguna,
si non esta, que dizen ser sola vna
de todas quantas nuestro Señor crio.
Aquellos que ovieron desta aue fablado,
escriuen el aguila ser semejante
en sus facciones, saluo por delante
los pechos e el cuello que tiene dorado;
e la cabeza de cabello encrespado,
con toda la otra parte argentada,
si non la cola que tiene colorada;
dela qual el nombre es Fenix llamado ${ }^{26}$.

En este sentido, hallamos también la imagen en texto de Juan de Padilla el Cartujano, posiblemente el mejor imitador de Dante después de Mena. Y no olvidemos que la imagen del fénix se halla presente en la Commedia ${ }^{27}$. Dicho texto de Juan de Padilla, perteneciente a Los Doce Triumphos de los Doze Apostoles en coplas de arte mayor, inserta el ave fugazmente, a manera de alusión, dentro de una descripción geográfica salpicada de ornamentación mítica, en donde, de nuevo, aparece Oriente, medio en este caso -Siria, Arabia, Petra- como visión de quien "se abaxa a contemplar las cosas terrenales»:

Debaxo del alto Zenith, do tenia
su monte divino la santa Solima,
puesto en el quarto serenico clima,
allí do levada mi mente se vía.
Y vimos a Syria con su compañía
la Comagena, do vi que se otea
Arabia desierta, llamada Petrea,
y toda la tierra do Fenix se cría,
distante no mucho del alta Judea

No dejaré de citar, en esta misma línea, la aparición de la imagen del fénix en algún texto del Laberinto de Juan de Mena, concretamente las coplas XXXVII y CCXLIII, dentro de las coordenadas de las visiones maravillosas, en las que no puede faltar la incidencia del mito, con descripción de un área

${ }^{26}$ Cancionero Castellano del Siglo XV. Ordenado por R. FoulCHÉ DelBOSC, Madrid, BAILLY BAILLIERE, 1915, II, 424, p. 155 y ss. estrofas 202 y 203.

27 Infierno, XXIV, 92-125, en virtud de su fabulosa muerte y resurrección, y muy posiblemente inspirada por la Historia Natural de Plinio o por el Tesoro de Brunetto Latini, otras veces cit. Vid., de todas formas, y al respecto, el vol. I, p. 270 de la ed. de La Divina Commedia debida a Natalino Sapegno, Firenze, la Nuova Italia Editrice, 1974.

28 "Los Doce Triumphos de los doze Apostoles, fechos per el Cartuxano, professo en Santa Maria de las Cuevas en Sevillaw, Cancionero Castellano del Siglo XV, cit., I, p. 300, cap. V, estrofa 2. 
geográfica medio-oriental, usual en la ubicación de nuestra imagen, en el primer caso; en relación a las cenizas, materia genética transformadora de la muerte y resurrección del ave, en el segundo:

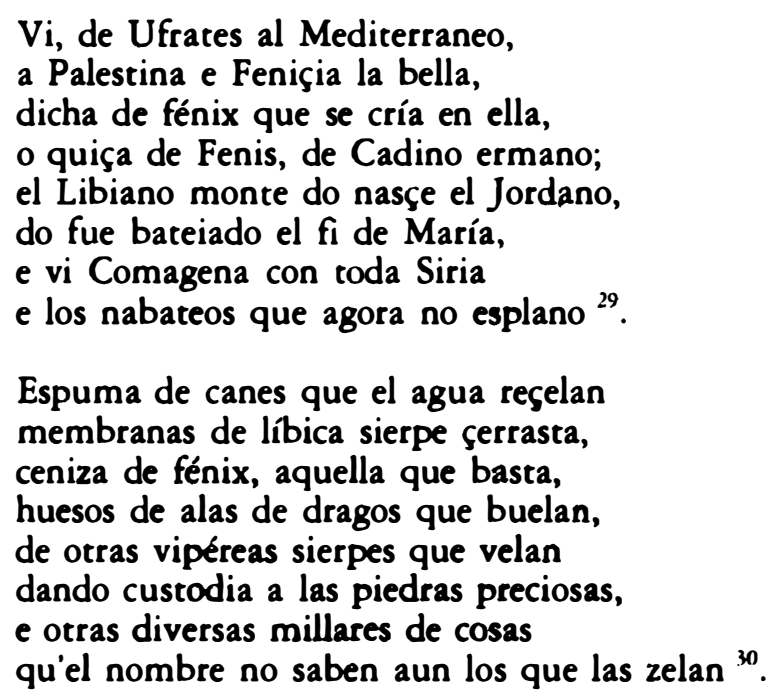

Por otro lado, en la propia obra del mismo Juan de Mena podemos ejemplificar proyecciones de la imagen del fénix en los segundos derroteros que anunciábamos antes y que tienen que ver con una formulación indirecta de la imagen a través de un determinado proceso retórico. En estos derroteros, según yo creo, la presencia de la imagen del fénix, más allá de una posible filiación con las obras naturalísticas antiguas o las enciclopedias doctrinales y bestiarios medievales, se halla en relación con la tradición instaurada o fijada por la poesía petrarquista. Porque, en efecto, dentro de la lírica amorosa de Francesco Petrarca, el ave fénix pasa a simbolizar: ya a la mujer amada, dentro de un arquetipo de femineidad que parece bastarse a sí misma (de ahí que quien la sustenta se haga inalcanzable para el hombre); ya al propio amante doliente,

29 Laberinto de Fortuna, XXXVI, ed. de Miguel Ángel PÉREZ Priego, Madrid, Espasa Calpe, 1989, con posible inspiración en la descripción, señalada por el propio Pérez Priego en el cap. V del Speculum naturale de Vicente de BeaUvaIS: «Fenix Cathini frater de Thebis Aegyptiorum in Syriam provectus apud Sydonem regnavit, eamque provinciam ex suo nomine Feniciam appellavit», op. cit., p. 75-76, n. 292.

30 Laberinto de Fortuna, CCXLIII, ed. cit., El mismo Pérez Priego, citando, a su vez, a Ma. Rosa LIDA, Juan de Mena, poeta del preerrenacimiento español. El Colegio de México 1950, p. 81, señala las Metamorfosis ovidianas, VII, 275, como fuente probable: «His et mille allis postquam sine nomine rebus». Pero no hay mención de fénix. Hay que añadir que sí existe, en cambio, en las mismas Metamorfosis, XV, 392-400: «Una est, quae reparet seque ipsa reseminet, ales; Assyrii phoenica vocant (...)», aunque en este texto de Mena la aparición del fénix, en el entramado de una enumeración, me parece demasiado fugaz y puntual para adscribirle en sí misma una filiación única. 
siervo consumido en el fuego de su amor (y no es mi intención en estos momentos ocuparme de otra imagen ígnea como la de la salamandra), fuego al que, sin embargo, no sólo resiste, sino que en él renace, para consumirse nuevamente en su llama.

El ave fénix, como emblema de Laura, alcanza en la obra petrarquesca una recurrencia tan sólo excedida por la gentile pianta, el lauro, con innumerables ejemplos esparcidos a lo largo del Canzoniere ${ }^{31}$ y de la obra latina ${ }^{32}$, pasándose luego, por esta vía, a la constitución de una tópica que alcanzará ya a los cuatrocentistas italianos, antes de llegar al paroxismo repetitivo que el tópico presentará en el quinientos ${ }^{33}$. Y, naturalmente, entre los españoles, desde Boscán, con sus coplas octosilábicas, de cancionero, Las cosas de menos pruevas, réplica de la canción Standomi un giorno ${ }^{34}$.

Esta designación del fénix por su belleza única entre las aves, en comparación a la amada, bella entre las bellas, es también la que nos ofrece Juan de Mena en la estrofa sexta de una composición octosilábica registrada en varios cancioneros: el de Estúñiga ", por el que enseguida citamos, el de Herberay des Essarts ${ }^{36}$, el Cancionero de Roma ${ }^{37}$, Cancionero llamado Vergel de Amores ${ }^{38} . .$. Se

" "Questa fenice de l'aurata piuma/al suo bel collo, candido, gentile/forma senz' arte un si caro monile/ch'ogni cor addolcisce e'l mio consuma» (RVF, CLXXXV, vv. 1-4); «Non da l'ispano Hiber a l'indo Ydaspe/ricercando del mar ogni pendice,/né dal lito vermiglio a l'onde caspe,/né'n ciel né' $n$ terra è più d' una fenice» (RVF, CCX, vv. 1-4): «E quest'l nido in che la mia fenice/mise l'aurate e le purpuree penne?» (RVF, CCCXXI, vv. 1-2); «Una strania fenice, ambedue l'ale/di porpora vestita e'l capo d'oro,/vedendo per la selva, altera e sola» (RVF, CCCXXIII, vv. 49-51). Citamos las RVF por la ed. de Gianfranco CONTINI, Torino, Einaudi, 1975.

${ }_{32}$ Es constante su presencia en las Familiares (Ad Sennucium Florentinum, IV, 14; Ad Guido Sete, V, 17, por ejemplo), pero, a decir verdad, en contextos distintos, no precisamente amorosos, y sin referencia a la amada del poeta. Vid. la ed. de Ugo DotTr, Le Familiari, Urbino, Argalia, 1974, 2 vols, I. pp. 456-457 y pp. 584-585.

${ }^{33}$ Vid. para la repercusión de la imagen en el petrarquismo italiano y español del cuatrocientos y quinientos, mi op. cit. Imágenes petrarquistas, pp. 305 y ss.

${ }^{34}$ Relación muy bien estudiada por Antonio ARMISÉN, Alegoría e imitación en las coplas de Boscán "Las cosas de menos pruevas», "Boletín de la Biblioteca de Menéndez Pelayo», LIX (1983), pp. 79-140. Vid. también el estudio de Fredi CHIAPPELLI, Studi sul linguaggio del Petrarca. La canzone delle visioni (V. «La strofa della fenice»), Firenze, Olschki, 1971, pp. 106-138.

35 Ed. de Nicasio Salvador Miguel, Madrid, Alhambra, 1987, pp. 64-65, vv. 6170.

${ }^{36}$ Le chansonnier espagnol d'Herberay des Essarts (XVe siècle), ed. de Charles V. AUBRUN, Bordeaux, Féret et Fils, 1951, p. 102, vv. 61-70.

"Ed. M. Canal GómeZ, Florencia, Sansoni, 1935, I, p. 19, vv. 61-70.

${ }^{38}$ Zaragoza, por Germán NÁGERA, 1551, Reimpresión en Valencia, Castalia, 1950, f. ${ }^{\circ}$ vij. 
trata de la canción «Guay de aquel hombre que mira» ${ }^{39}$ :

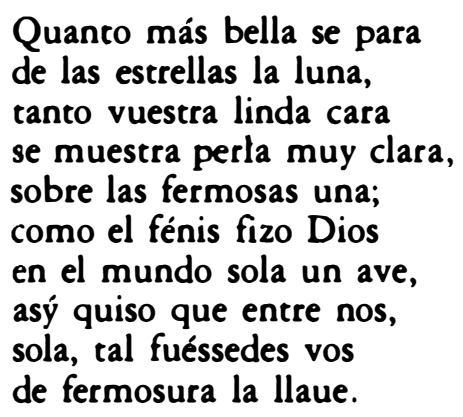

Pero caso que no es único en la poesía cancioneril, porque igualmente se registra, designando a la amada, en texto de Alvar Gómez, muy significativamente, el traductor del Triunfo de Amor de Francisco Petrarca que contiene el Cancionero de Gallardo:
Cansada ya de bevir
la fenix de Arabia cria
busca fuego
do se dexa consumir, y a la bida que tenia torna luego;
tan sola bos como aquella
al fuego del alma estais retrida, naçiendo a cada çentella, sin que jamas os partais de la bida ${ }^{40}$

O igualmente, en el «Conjuro de Amores», de Costana, «La grandeza de mis males»:

\author{
Aquella rauia sin ruego \\ aquel dolor del abismo \\ $\tan \sin$ uicio \\ con qu'el Fenix haze el fuego \\ en que haze de sí mismo \\ sacrificio, \\ si crueza tal consiente \\ tal dolor tú, siempre tengas \\ por quererme,
}

39 Para la presencia de la composición en la tradición manuscrita, vid. el núm. 0006, p. 1 del t. II del «Indice Maestro» del cit. Catálogo Indice de la Poesia Cancioneril del Siglo XV de Brian DUTTON. Señaló la filiación petrarquesca de esta imagen M. Ángel PÉrez PRIEGo en Juan de Mena. Obra lírica, Madrid, Alhambra, 1979, p. 96.

40 "Al abe fenix quando muere» en el cit. Cancionero de Gallardo, ed. crítica por José Ma. AZÁCETA, Madrid, CSIC, 1962, p. 154. 
que la misma ansia que sience sientas tu hasta que vengas a valerme ${ }^{41}$.

Pero en ambos casos, y como habrá podido observarse, la identificación amada-fénix no se realiza a la manera ornamental de descripción suntuaria, sino en virtud del continuo renacer del ave y en relación al efecto que así cobra en la visión y el sentir del enamorado, proyectando tal vez, en la constante resurrección del fénix-amada, la perduración renovada de su propio deseo. Porque, en efecto, habíamos ya adelantado que la imagen puede representar también al mismo amante agonizando en su pasión, según los cánones acuñados por la tradición petrarquista originada en la canción Qual più diversa e nova ${ }^{42}$ y seguida de cerca por los petrarquistas del cuatrocientos ${ }^{43}$.

Sin embargo, en esta otra confrontación ejemplificativa de la imagen, la propia poesía italiana, como asimismo la trovadoresca, contaba ya con varias manifestaciones que pudiéramos ilustrar en las trovas de Richard de Barbezieux, uno de los escasos ejemplos presentados por la lírica provenzal y señalado por Flavio Catenazzi ${ }^{44}$, con otros varios, dentro de la propia escuela siciliana: en la poesía de Inghilfredi o Ciolo della Barba "s, y, posteriormente, en las Rime de Giovanni Boccaccio, en donde la imagen se detecta igualmente ${ }^{46}$.

41 Cancionero General Recopilado por Hernando del CASTILlO, Valencia, 1511, LXXXVII v. La composición aparece igualmente en el Cancionero llamado Vergel de amores, cit., XXVI v.-XXIX v. atribuido erróneamente a Diego López de Haro. Para la tradición manuscrita de la misma, vid. el núm. 0873 del Catálogo Indice de Brian Dutton, I, p. 23.

${ }^{42}$ "La onde il dí vèn fore,/vola un augel che sol senza consorte,/di volontaria morte/rinasce et tutto a viver si rinova./Cosí sol si ritrova/lo mio voler, et cosí in su la cima/de' suoi alti pensieri al sol si volve et cosí si risolve,/et cosí torna al suo stato di prima;/arde, et more, et riprende i nervi suoi,/et vive poi con la fenice a prova» (RVF, CXXXV, vv. 5-15).

${ }^{43}$ Lorenzo de'Medici (Parmaso cit., XI, VI, 1089, vv. 12-14); Serafino dell'Aquila (strambotto 158 según la ed. de Barbara BAUER-FORMICONI, Die strambotti des Serafino dall'Aquila, Wilheim Fink Verlag München, 1967). Pero vid., para mayores pormenores al respecto, mi estudio cit. Imágenes petraquistas, pp. 305-306

44 «E s' ieu pogues contrafar/Fenis, don non es mais us,/que s'art e pois resortz sus,/eu m'arsera, car sui tan malananz", L'influsso dei provenzali sui temi e immagini della poesia siculo-toscana, cit., p. 238

45 "Che mi consumo e ardo,/ch'eco rinovello com'fenice face". (Inghilfredi, XLI, 1, vv. 15-16); "onde la mia speranza si conforta:/com'fenice, per rinovar s'amorta» (Ciolo della Barba, XXXVI, 1, vv. 19-20), entre otros inventariados por Walter PAGANI en su Repertorio, cit., p. 447-448.

46 "Cosí, del mio fin dubbio, ardendo spero/nel fuoco rinnovar come fenice,/e questo d'ogni doglia è medicina», Rime, XXIII, vv. 11-14. Opere Minori in Volgare, a cura di Mario MARTI, Milano, Rizzoli, 1963. 
Tal peculiaridad, que se constituirá en tópico manido entre los poetas del Renacimiento y del Barroco, tanto en Italia como en España (y supongo que, más o menos, en los mundos poéticos en donde el petrarquismo alcanza) ${ }^{47}$, se registra, igualmente, en varias composiciones cancioneriles, aunque, dada la variedad de orígenes que tal identificación, fénix-amante, presenta en este caso, me parece arriesgado proponer una filiación petrarquista única; pero no así una fijación, llevada a acabo por la fuerte impronta de los modelos del Canzoniere.

En una canción de Quirós, «No sé que llame ventura», confrontándose el poeta con el ave, rememora así el motivo específico de la muerte y resurrección en el fuego, por voluntad propia, en un hallarse a sí mismo, al perder, paradójicamente, la vida:

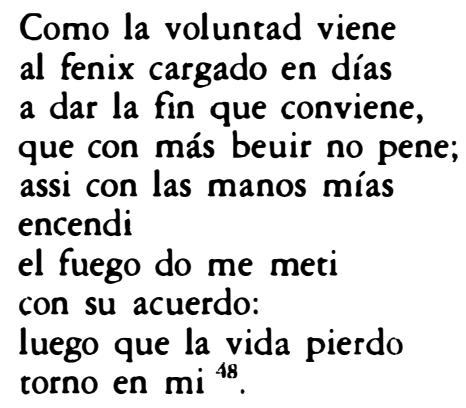

Más específicamente, Garci Sánchez de Badajoz, presentará varios ejemplos de amante, quemándose continuamente en el fuego de su pasión amorosa a la manera de fénix. Así, por ejemplo, en sus «Lamentaciones de amores»:

\author{
Ave fenix que sin par \\ tu te quemas y deshazes \\ en el fuego, \\ y otra nueva sin dudar \\ a la ceniza que hazes \\ naçes luego; \\ Ansi yo triste mezquino
}

17 Así, por ejemplo, en el petrarquismo inglés, en transformaciones petrarquistas estudiadas por Silvia RUFFOFIORE, Donne's transformations of Petrarchan imagery in the Canonization, «Italian Quarterly», 73-74 (1975), pp. 53-61. Y en el petrarquismo francés, en Maurice Scève, el poeta del unicornio, pero con una importante incidencia de la imagen del fénix en su Délie (III, 2), incidencia puesta de relieve por Paul ARDOUIN en su bellísimo estudio, La Délie de Maurice Scève et ses cinquante emblèmes, Paris, Nizet, 1982, pp. 301315.

48 Cancionero General, cit., CCVII v. Asimismo en Cancionero Castellano del Siglo XV, cit., II, pp. 286, 560, por donde citamos. ID 6716 en el Catálogo Indice de la Poesía Cancioneril del Siglo XV de Brian DurToN. 


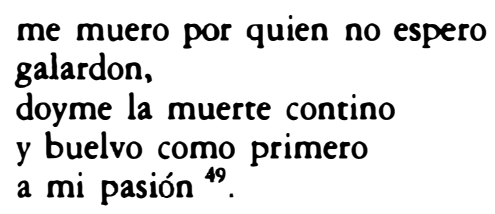

Y como fénix, pero en una interpretación negativa, que, en principio, no está en el mito, donde el sentido de la singularidad es siempre positivísimo, lamentará Garci Sánchez su soledad de amor, al considerarse, como el fénix, único y, por lo tanto, solo. Tal sucede en las «Glosas sobre la lamentación, lágrimas de mi consuelo»:

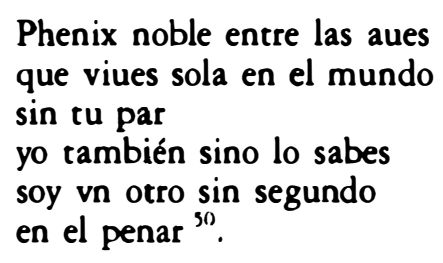

Pero preciso será mentar también otras confrontaciones que la imagen del fénix ofrece en la propia lírica de cancionero. Por ejemplo, la del ritual y elegía funeraria; donde el ave se nos muestra como imagen ejemplar, ligada a la inmortalidad de difuntos de rango. Tal el caso de las "Coplas que hizo Hernán Pérez de Guzmán a la muerte del obispo de Burgos don Alonso de Cartagena», contenida en el Cancionero General de 1511:

El fenix de nuestra esperia
ciente y muy virtuoso
ya dexo la gran miseria
deste valle lagrimoso $"$.

Y en el mismo Cancionero la sextina en dodecasílabos de Trillas y Crespí de

49 Citamos por la ed. de Julia CASTILlO, Cancionero, Madrid, Editora Nacional, 1980, p. 275, vv. 115-120. Composición 4676 de NN 14 (7-11) en el Catálogo Indice... de Brian DUTTON cit. en versión parcial. También parcial en el Cancionero Castellano del siglo XV, cit., II, p. 653, 1080, con alguna variante. Vid., además, y de manera general, para este poema, el estudio de Patrick Gallagher, The life and works of Garci Sánchez de Badajoz, London, Tamesis Books, 1968, pp. 247 y ss.

so Citamos nuevamente por la ed. de Julia Castillo, p. 401, vv. 108-113. Se trata de una composición hallada por la autora en el Ms. 1577, núm. 143 de la Biblioteca de Palacio (Madrid), que no incluye Brian DUTTON en su Catálogo-Indice, pero de lo que da noticia en I, p. 88.

${ }^{31}$ Ed. cit. f. ${ }^{\circ X X X V i i ~ r . ~ I g u a l m e n t e, ~ e n ~ e l ~ C a n c i o n e r o ~ d e ~ p o e s i ́ a s ~ v a r i a s . ~ M s . ~} 617$ de la Biblioteca Real de Madrid, edición de José J. LABRADOR, C. Ángel ZORITA y Ralph D. FrANCO, Madrid, El Crotalón, 1986, núm. 86, pp. 147, vv. 88-91. Para la tradición manuscrita, vid. el núm. 1937 del Catálogo-Indice de Brian Dutton, II, p. 46. 
Valldaura, «La muerte que tira con tiros de piedra» dedicada a la Reina Isabel la Católica, ya difunta, fénix de las reinas, imagen que se repetirá en cada estrofa y en el envío final:

La muerte que tira con tiros de piedra
matando de todas las reynas el fenix
ennoblescer quiso vn baxo sepulcro
daquella tan alta despues dela virgen
y santas benditas gano tal triumfo
que fue deste mundo la firme columpna $\$ 2$

Composición posiblemente influida por la propia poesía de Petrarca ", pero tratándose de un poeta del círculo literario valenciano, acaso también por la de Ausias March ", quien en su canfo "Mon bon senyor puix que parlar en prosa», había aunado la imagen a la realeza en la figura de Alfonso $V$ el Magnánimo ". De hecho, el fénix podía transformarse, y así cristalizó en tiempos de los RRCC, en figura quimérica de la heráldica, de clara derivación mitológica ${ }^{36}$.

Como por la vía de las desviaciones, transformaciones y transgresiones significativas que la imagen sufre o, sencillamente, registra en la poesía de cancionero, su expresión se ejemplifique también, lógicamente, en la poesía cancioneril a lo divino para designar, indistintamente, por el carácter bisexual o asexual del ave, a Cristo y, como sucede en una composición anónima recogida en el Cancionero Espiritual, a la Virgen María:

Ave fénix singular

y sin par

32 Cancionero General, 1511, cit., clxxxviii r., estrofa 1.a; núm. 6690 en el CatálogoIndice de Brian DUTTON, II, p. 129, aunque no presenta referencias de tradición manuscrita. Si, en cambio, aparece en la 2." ed. del propio Cancionero General de 1514.

33 Vid. al respecto, el artículo de Francisco RICO, A fianco di Garcilaso: poesía italiana e poesia spagnola nel primo cinquecento, "Studi petrarcheschi», IV (1987), p. 235.

${ }^{54}$ Es un hecho en el que, con acierto, insiste mucho Joan FUSTER en relación al petrarquismo valenciano, aun cuatrocentista, en sus Lectures d'Ausias March en la València del segle XVI, "Discurs de Recepció de la Solemne Investidura de Doctor Honoris Causa, Universitat de Barcelona, 31 d'octubre de 1984. Ahora en Llibres i problemes del Renaixement, Publicacions de l'Abadia de Montserrat, 1989, pp. 65-100.

" «Un fénix hom dona semblant requer,/e Déu permet que Amor aquests juny/e mostra's clar portant aquell de luny/per fer unir dos cors en un volern: Poesies, Barcelona, Barcino, 1959, V, CXXIIb, vv. 33-40.

${ }^{36}$ Vid. Martín de RiQuer, Manual de Heráldica Española, Barcelona, Apolo, 1942, p. 34. La reciente publicación, Heráldica castellana en tiempos de los Reyes Católicos, Barcelona, Biblioteca Filológica Quaderns Crema, 1986, no incluye, en cambio, el fénix entre las aves estudiadas. 
sin hallar quien se atreva

a osarse te igualar

hecha para reparar

los daños de la madre eua"

De hecho, la predisposición a la divinización de la imagen se hallaba implícita en el origen del mito y siempre en potencia, desde su tratamiento antiguo de carácter sagrado en los jeroglíficos egipcios o en alguno de los primeros bestiarios románicos, como el de Philippe de Thaün. No es de extrañar, pues, que en la poesía de cancionero, como, por lo demás, en la espiritual española de los Siglos de Oro, emerja de nuevo con significado sacro ${ }^{\text {s. }}$.

Y sabido es que toda manifestación excesivamente áulica o/y espiritual despierta y posibilita una reacción de signo contrario, situándose en el filo de lo burlesco o, simplemente, de lo humorístico. En especial, cuando de puro repetida se hace tópica; lo que, por supuesto, ocurre con la imagen del fénix, ya sea designando a la dama-amada, ya al propio poeta-amante. Este último es el caso presentado por Salaçar el Hermitaño en la poesía dialogada «Desposósete tu amiga»: ante la noticia, nada trágica, por el tono que adopta, de la boda de su amada, un dialogante enamorado burlón, acogiéndose a las propiedades transformacionales que el mito del ave propicia, decide aprovecharlas y «hacer como» si ave fénix fuese: morir, renacer a un nuevo y embriagador amor y reirse del antiguo, poniendo en solfa la constancia del sentimiento:

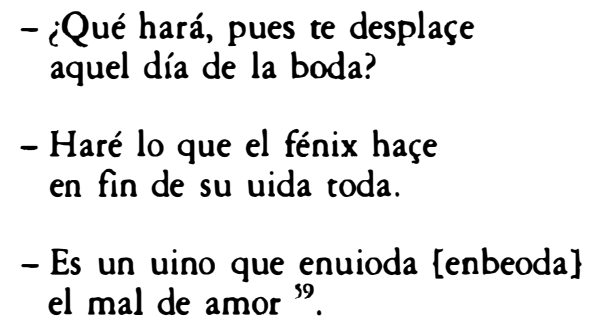

En fin, una función más entre las varias que presenta la imagen en la poesía española de cancionero.

\section{MARÍA PIlAR MANero SOROlLA Universidad de Barcelona}

37 Valladolid, 1549. Reimpreso directamente de la primera edición. Con un estudio preliminar de Bruce W. WARDROPPER, Valencia, Castalia, 1954, p. 56.

${ }^{88}$ Por lo que se refiere a la tradición franciscana y carmelitana puede consultarse mi artículo El rvuelo del espíritu» en la obra de Santa Teresa. Primeras Aproximaciones. «Homenatge a Antoni Comas», Universitat de Barcelona, 1985, pp. 218 y ss.

59 Cancionero de Poesias Varias. Ms. 617 de la Biblioteca del Palacio Real cit., n. ${ }^{\circ} 194$, p. 244. N. 2016 en el Catálogo-Indice de Brian DuTTON cit. 


\section{RÉSUMÉ}

L'article analyse et étudie dans le détail la présence de l'image du Phénix dans la poésie des recueils de chansons. Après avoir délimité les chansonniers étudiés et fixé l'espace rhétorique de l'image poétique, on décrit celle du Phénix et on trace une brève histoire de son apparition. Ensuite l'étude porte sur la poésie des recueils de chansons espagnoles, en présentant et en analysant des textes de Fray Iñigo de Mendoza, Juan de Padilla, le Cartujano, Juan de Mena, Alvar Gómez, Costana, Quirós, Garci Sánchez de Badajoz, Hernán Pérez de Guzmán, Crespí de Valldaura, etc., tout en signalant, dans chaque cas, la possible origine du modèle imité et la description, le sens, la référence et l'ulitilité de l'image.

\section{SUMMARY}

The article registers and analyses the presence of the image of the Phoenix in a collection of poetry and songs. After defining the scoop of the studied collection of songs and the rhetorical space of the poetic image, we describe that of the Phoenix and explain briefly the story about its appearance. Afterwards, we centre our study around the Spanish poetry songs, presenting and analyzing texts by Fray Iñigo de Mendoza, Juan de Padilla, le Cartujano, Juan de Mena, Alvar Gómez, Costana, Quirós, Garci Sánchez de Badajoz, Hernán Pérez de Guzmán, Crespí de Valldaura, etc. We also underline, for each case, the possible origin of the imitated model and the description, sense, reference and function of the image. 